\title{
Biomasses et activités bactériennes dans la retenue et à l'aval du barrage de Petit-Saut (Guyane) : influence sur les émissions de méthane et la consommation d'oxygène
}

\author{
Biomass and bacterial activity in the reservoir and \\ downstream of Petit-Saut dam (French Guiana): \\ impact on methane emissions and oxygen consumption
}

\author{
J.F. Dumestre(1), L. Labroue (1), C. Galy-Lacaux ${ }^{(2)}$, \\ C. Reynouard(3), S. Richard(3) \\ (1) Laboratoire d'Hydrobiologie (UMR CNRS/UPS 5576), Université Paul-Sabatier, 118, route \\ de Narbonne. 31062 Toulouse cedex, France. \\ (2) Laboratoire d'Aérologie (UMR CNRS/UPS 5560), OMP, 14, avenue Edouard-Belin, 31400 \\ Toulouse France. \\ (3) Laboratoire Environnement de Petit-Saut, $B P n^{\circ} 823,97388$ Kourou cedex, Guyane.
}

Résumé. - La biomasse, la productivité et les activités bactériennes ont été suivies au cours de l'année 1995 dans la retenue de Petit-Saut (Guyane) et dans le fleuve Sinnamary, à l'aval de l'ouvrage. Les mesures effectuées montrent une augmentation régulière de la biomasse dans le lac, en particulier sous l'oxycline, suivie d'un début de stabilisation à la fin de l'année. On observe une augmentation similaire dans le fleuve mais avec des irrégularités tributaires du débit, c'est à dire du temps de séjour des organismes en suspension.

En ce qui concerne les activités spécifiques bactériennes, l'arrêt soudain des émissions de méthane à la surface du lac est le résultat d'une consommation active du gaz dissous au niveau de l'oxycline. Le déclenchement de cette activité semble corrélé avec la diminution de la concentration en sulfures, elle même apparemment liée au développement d'une microflore anaérobie phototrophe sous l'oxycline.

Dans le fleuve, l'oxydation des sulfures de fer n'est responsable que d'une faible partie de la consommation d'oxygène. L'oxydation du méthane non dégazé est la cause essentielle de la désoxygénation de l'eau. Là aussi, le développement de cette activité ne se produit qu'après la disparition des sulfures, malgré la présence simultanée d'oxygène et de méthane. Cependant, cette hypothèse demande confirmation.

Mots-clés. - Bactéries, méthane, méthanotrophes, sulfures. 
Abstract. - Biomass, productivity and bacterial activity were studied during 1995 in the Petit-Saut reservoir and downstream, in Sinnamary River (French Guiana). Biological analyses showed a regular increase in bacterial abundance, particularly below the oxycline, followed by a stabilizing trend at the end of the year. In the river downstream, we observed a similar increase which was depended on the evacuated flow, or the residence time of suspended organisms.

As concerns specific bacterial activities, the sudden halt in methane emissions at the surface of the lace, resulted from intense consumption of the dissolved gas at the oxicline level. The start of this phenomenon seems related to the observed decrease in sulfide concentrations, which is apparently linked in turn to the development of phototrophic anaerobic sulphur-oxidizing bacteria under the oxicline.

In the Sinnamary River, iron sulphide oxidation induces only a minor part of the oxygen consumption. Oxidation of non-degassed methane is the major cause of the low oxygen concentrations downstream. This begins only after the disappearance of sulphides, despite the presence of methane and oxygen. However, this hypothesis must be investigated.

Key words. - Bacteria, methane, Methanotrophs, sulphides.

\section{INTRODUCTION}

La retenue de Petit-Saut présente bien des différences avec les plans d'eau des climats tempérés ou froids, traditionnellement étudiés par le laboratoire d'Hydrobiologie de l'Université Paul-Sabatier de Toulouse. II en est résulté une "phase de latence adaptative", concrétisée par les premières campagnes d'études de l'année 1995.

En effet, outre les conditions bio-climatiques et fonctionnelles typiques des milieux équatoriaux (lac méromictique chaud), le piégeage de la matière organique de la forêt inondée lors de la mise en eau a provoqué des phénomènes bien connus mais toujours impressionnants. La forte activité de dégradation de la matiere organique au fond du lac s'est traduite par la diffusion ou la mise en suspension d'éléments réduits dans la colonne d'eau, avec une nette prédominance du gaz méthane et des sulfures.
Ces éléments réduits, générés dans le fond du lac par les bactéries méthanogènes, la sulfhydrisation ou les bactéries sulfato-réductrices, constituent une source de substrats importante pour d'autres groupes physiologiques comme les bactéries méthanotrophes (aérobies) et les bactéries sulfo-oxydantes (chimio-lithotrophes aérobies et phototrophes anaérobies). Ils contribuent à la désoxygénation totale de l'hypolimnion du lac et à la désoxygénation partielle du fleuve Sinnamary à l'aval du barrage.

Les éléments réduits gazeux comme le méthane et l'hydrogène sulfuré qui s'échappent dans l'atmosphère participent à la modification des équilibres thermiques (effet de serre) ou chimiques (ozone, pluies acides). Ces problemes sont à l'origine des études entreprises depuis la mise en eau par des équipes du laboratoire d'Aérologie et du laboratoire d'Hydrobiologie de l'Université toulousaine, initialement pour évaluer l'impact du 
barrage vis-à-vis de la forêt équatoriale.

Après que nous ayons constaté l'importance des émissions gazeuses sitôt la mise en eau, il est apparu, environ un an plus tard, que les émissions cessaient brutalement, malgré des concentrations élevées dans la colonne d'eau (fig. 1). Par contre, la mise en exploitation de la centrale se traduisait par une forte consommation d'oxygène dans le fleuve, en liaison avec un mauvais dégazage du méthane. Ceci nous a conduit à privilégier l'étude des mécanismes microbiologiques à l'origine de l'oxydation du méthane et des sulfures dans le lac et dans le fleuve.

A cet effet, nous avons utilisé une large palette de méthodes en vue de tester leur adéquation avec le milieu étudié, avec des réussites diverses. Dans un premier temps, nous avons cherché à évaluer la biomasse bactérienne, sa productivité et son activité dans les domaines qui nous interessaient plus particulièrement, c'est à dire l'oxydation du méthane et des sulfures.

\section{MATÉRIEL ET MÉTHODES}

\subsection{Evaluation de la biomasse bactérienne totale}

Elle passe par la numération des cellules, l'estimation de leur volume et la conversion des volumes en biomasse carbonée.

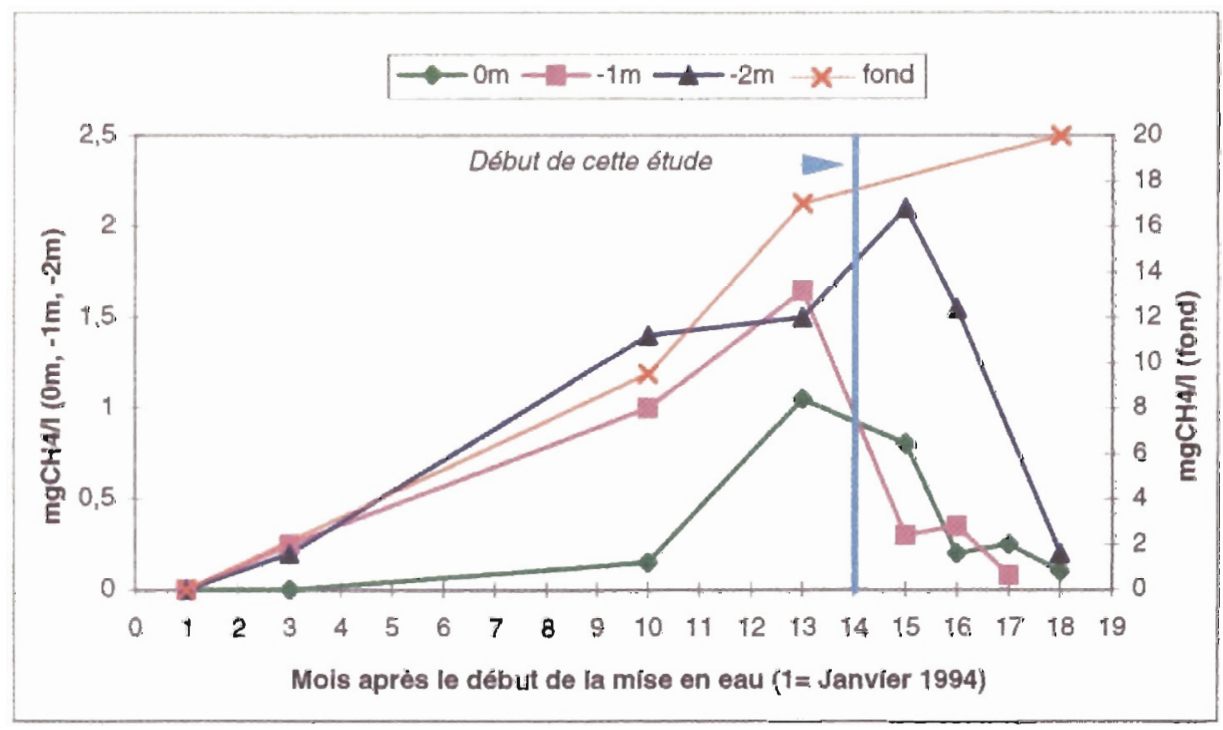

Fig. 1. - Evolution des concentrations en méthane dissous dans la colonne d'eau du lac de PetitSaut, au site BPS, depuis janvier 1994.

Fig. 1. - Variations of the dissolved methane concentrations in Petit-Saut lake water column, at the BPS site, since January 1994. 


\subsubsection{Dénombrement des bactéries totales}

Les bactéries sont dénombrées en microscopie à épifluorescence après marquage au DAPI (Porter et Feig, 1980). Le nombre de champs à dénombrer sur chaque lame est fonction de la précision désirée et du nombre moyen de bactéries par champs (Trousselier et al., 1985). Nous comptons deux lignes sur 30 champs, avec un nombre moyen de 100 bactéries par champs. L'intervalle de confiance de la moyenne au seuil de sécurité de $95 \%$ est égal à $+/-$ le double de l'écart-type de la moyenne.

\subsubsection{Volumes cellulaires}

Le volume cellulaire est obtenu à partir des mesures de taille des bactéries. Sur chaque lame, des clichés sont pris grâce à une caméra Hamamatsu CCD avec une ouverture maximale du diaphragme. Un agrandissement de ces clichés en présence de la photo d'un micromètre prise avec la même caméra vidéo, permet de mesurer la taille apparente des bactéries et de la convertir en taille réelle. 150 bactéries sont ainsi mesurées pour chaque échantillon (Torreton, 1991).

Chaque bactérie est assimilée à un cylindre compris entre deux demisphères pour les bâtonnets, à une sphère pour les coques. Le volume cellulaire est donc calculé suivant la formule suivante (Bratbak, 1985) en fonction de la longueur (L) et de la largeur (I) des bactéries:

$$
V=\left.(\Pi / 4)^{\star}\right|^{2 *}(L-I / 3)
$$

Nous calculons ainsi le biovolume pour chaque classe de taille: $L$ et I variant entre $0,165 \mu \mathrm{m}$ et $2,5 \mu \mathrm{m}$.

\subsubsection{Conversion en biomasses carbonées}

Cette conversion est réalisée à l'aide de la relation suivante, déterminée à partir des données de Simon et Azam (1989) :

$$
\mathrm{C}=92^{*} \mathrm{~V}^{0.598}
$$

$V$ en $\mu \mathrm{m}^{3}$ et $C$ en $f g\left(f g=10^{-15} \mathrm{~g}\right.$ ).

Ainsi, à partir du nombre de bactéries par classe de taille et de la biomasse carbonée correspondante, nous pouvons déterminer la biomasse carbonée totale et d'autre paramètres tels que la biomasse individuelle moyenne $\left(B_{\text {moyen }}\right)$, le biovolume total et le biovolume individuel moyen $\left(V_{\text {moyen }}\right)$.

\subsection{Mesure de la production bactérienne totale}

Elle peut être obtenue en mesurant le taux moyen de division cellulaire, ce qui suppose que la masse cellulaire individuelle reste constante, ou en utilisant des constituants cellulaires marqués (traceurs radioactifs) dont l'incorporation est considérée proportionnelle à la croissance.

\subsubsection{Mesure des taux moyens de division cellulaire}

L'eau étudiée est prélevée dans une seringue stérile de $60 \mathrm{ml}$ à travers le septum du $T$ placé en amont de la tête de la pompe péristaltique afin de 
préserver les conditions d'anoxie dans le cas des eaux profondes.

Ceci fait, $5 \mathrm{ml}$ de chaque seringue sont prélevés et fixés au formol $(4 \%$ en concentration finale), en vue d'un comptage par épifluorescence au DA$\mathrm{PI}$ pour déterminer le nombre de bactéries à $\mathrm{t}=0$. Les cultures sont mises à incuber 4 heures dans les conditions du milieu. Des tests de croissance préalables nous ont permis de constater que ce temps était nécessaire pour pouvoir observer une croissance significative lors du comptage au microscope. On considère que pendant ce laps de temps, relativement court, les conditions de substrat varient peu et n'entrainent pas un changement de taux de croissance. Au bout de 4 heures, $5 \mathrm{ml}$ sont à nouveau fixés au formol.

Pour le comptage, il est essentiel d'attacher une grande importance à la préparation des lames et de compter un nombre de champs élevé pour réduire l'intervalle de confiance (IC95\%) des dénombrements obtenus. De cette maniere, nous avons obtenu un intervalle de confiance de 5 à $8 \%$.

Le taux moyen de division cellulaire $\left(h^{-1}\right)$ est donné par la relation suivante :

$$
\mathrm{R}=1 / 4 \ln (\mathrm{Nt} 4 / \mathrm{Nt0})
$$

avec $:$ Nt0 $=$ nombre de bactéries à to to $+4 h$.

$\mathrm{Nt} 4=$ nombre de bactéries à

Son intervalle de confiance maximal est calculé ainsi : $R 1<R<R 2$ avec : R1 $=1 / 4 \ln [(\mathrm{Nt} 4-$ IC $95 \%) /($ Nt0 + IC $95 \%)]$

$\mathrm{R} 2=1 / 4 \ln [(\mathrm{Nt} 4+$

IC $95 \%) /(\mathrm{NtO}-\mathrm{IC} 95 \%)]$

II est donc important d'obtenir un IC $95 \%$ minimal pour limiter l'intervalle de confiance de $R$.

\subsubsection{Mesure de la production carbonée par incorporation de traçeurs radioactifs}

En vue de déterminer la production bactérienne carbonée et parallèlement l'activité bactérienne dans la retenue de Petit-Saut, nous avons utilisé deux méthodes couramment employées depuis plusieurs années: l'incorporation de thymidine tritiée dans le matériel génétique bactérien et l'incorporation de leucine tritiée dans les protéines.

L'incorporation de thymidine dans l'ADN est proportionnelle au taux de division cellulaire et donc à la productivité du peuplement bactérien (Fuhrman et Azam, 1980); tandis que l'incorporation de leucine dans les protéines permet de mesurer directement un accroissement de la biomasse carbonée (Kirschman et al., 1985).

Ces deux méthodes sont couramment utilisées au laboratoire d'Hydrobiologie (Servais et Lavandier, 1993; Petit, 1993). Cependant, il convenait, pour des milieux différents comme Petit-Saut, d'adapter le protocole. Dans un premier temps, nous avons testé ces méthodes en appliquant des 
concentrations et des temps d'incubation arbitraires. Ceci a été fait lors de la campagne de mai 1995. À première vue, la méthode à la thymidine n'était pas satisfaisante, tandis que la méthode à la leucine donnait des résultats cohérents. En tenant compte des paramètres essayés en mai, nous avons donc revu les protocoles pour optimiser la méthode à la leucine et pour améliorer celle à la thymidine. II en est résulté les protocoles suivants qui ont été élaborés avec l'aide de P. Lavandier et M. Petit :

Prélèvements: Les échantillons d'eau sont prélevés à la seringue à travers le septum placé en amont de la pompe péristaltique afin de limiter les échanges gazeux.

Incubations: Les incubations d'échantillons de $4 \mathrm{ml}$ prélevés en zone aérobie ont été réalisées dans des flacons en polystyrène cristal de $40 \mathrm{ml}$.

Lors des incubations en zone anaérobie, il est essentiel de préserver les conditions d'anoxie du milieu; ainsi les échantillons de $8 \mathrm{ml}$ sont injectés rapidement après prélèvement dans des flacons en polypropylène de $8 \mathrm{ml}$, vissés hermétiquement (GarciaCantizano, Calderon-Paz, PedrosAlio, 1994).

Pour chaque concentration testée et pour chaque traitement, des essais et des blancs directement fixés au TCA sont réalisés en parallèle (concentration finale : $5 \%$ ).

Pour la thymidine, nous avons essayé, à nouveau, avec des échantillons prélevés à $-1 \mathrm{~m}$ et à $-15 \mathrm{~m}$ de profondeur, une gamme de concentra- tions croissantes en thymidine "chaude" allant de 20 à 250 nM. Ce$\mathrm{ci}$ afin de déterminer la concentration saturante à utiliser par la suite. A l'oxycline $(-4,5 \mathrm{~m})$ et à $-7 \mathrm{~m}$, une concentration arbitraire de $142 \mathrm{nM}$ a été adoptée.

Pour la leucine, les $K_{m}$ étant de l'ordre de $60 \mathrm{nM}$, nous avons testé une gamme de concentrations allant de 4,8 à $61,8 \mathrm{nM}$; cette gamme a été réalisée avec $4,8 \mathrm{nM}$ de leucine "chaude" et un ajoût complémentaire de leucine "froide". Un profil à la station BPS a été effectué aux profondeurs $-1 m,-4 m,-7 m$ et $-15 m$.

Au vu des résultats obtenus lors de la campagne de mai, le temps d'incubation a été fixé à 20 minutes, dans les conditions du milieu.

Les incorporations sont arrétées par adjonction d'acide trichloracétique (TCA) froid en concentration finale de $5 \%$. Pour les incorporations en zone anaérobie, l'échantillon est versé dans le TCA. Pour permettre une filtration plus rapide, seulement $4 \mathrm{ml}$ sont traités.

Traitement des essais: Pour la thymidine nous avons suivi les protocoles de Furhman et Azam (1982), Rieman (1984), Wicks et Robarts (1987). Les traitements au TCA froid seul et à la DNAse en supplément ont été réalisés à chaque fois en parallèle. Le fractionnement enzymatique à la Désoxyribonucléase I est utilisé pour déterminer la part de thymidine incorporée dans les proteines et I'A.R.N. La différence avec le traitement TCA froid seul permet de calcu- 
ler la vitesse d'incorporation dans I'A.D.N., uniquement.

Pour l'incorporation de leucine, nous avons suivi le protocole de Servais (1990). Le traitement au TCA froid est appliqué à toutes les concentrations, et celui au TCA chaud est appliqué en parallèle à la première concentration $(4,8 \mathrm{nM})$, afin de déterminer le rapport d'incorporation TCA chaud/TCA froid qui servira pour toutes les concentrations lors des calculs de vitesses d'incorporation. Le TCA chaud hydrolyse I'ADN et I'ARN; seules restent les proteines marquées.

Calcul des vitesses d'incorporation: En ce qui concerne la thymidine, les calculs de vitesse d'incorporation sont réalisés de la façon suivante, à partir des comptages de radioactivité donnés en DPM (désintégrations par minute) :

\section{$V=(D P M$ TCAf - DPM DNAse $)$ * $1000 / v * 60 / t$}

où : DPM TCAf = comptage du précipité au TCA froid - blanc

DPM DNAse = comptage du traitement à la DNAse I - blanc $v=$ volume de l'échantillon ( $\mathrm{ml}$ )

$\mathrm{t}=$ temps d'incubation $(\mathrm{mn})$

$\mathrm{V}=\mathrm{DPM}$ incorporés/l.h

Pour passer aux nanomoles de thymidine incorporées, la conversion suivante est effectuée:

$$
\text { Vthy }=V /(C * A S)
$$

où : $C=2,2 \cdot 10^{6} \mathrm{DPM} / \mu \mathrm{Ci}$

$\mathrm{AS}=$ activité spécifique de la thymidine $=46 \mathrm{Ci} / \mathrm{mmole}$ (pour ce lot)
Vthy $=$ nmoles incorporées/l.h

Pour la leucine, le calcul est quelque peu différent, car nous ne travaillons pas à saturation, la leucine ajoutée étant diluée dans le pool de leucine présente dans le milieu et dans la leucine endogène biosynthétisée (fig. 2). Par l'apport de différentes concentrations en leucine exogène inférieures à la constante de Michaëlis $\left(\mathrm{K}_{\mathrm{m}}\right)$, l'incorporation est proportionnelle à la concentration en leucine totale présente dans le milieu (loi d'ordre 1). Dans ces conditions, la vitesse d'incorporation de la leucine marquée est égale à l'inverse de la pente de la droite représentant la fonction :

DPM ajoutés/DPM incorporés par heure $=f$ (concentration) .

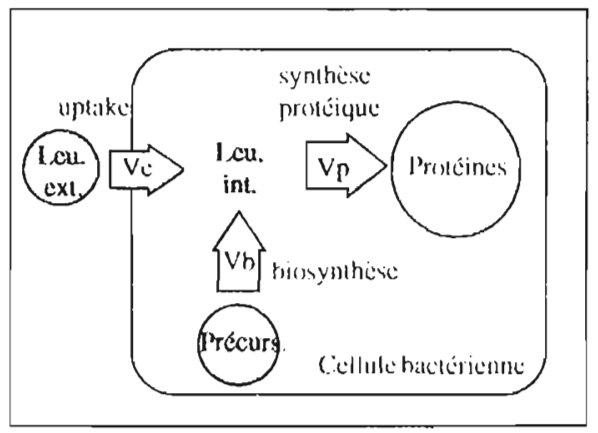

Fig. 2. - Voie de synthèse protéique incorporant de la leucine externe et de la leucine biosynthétisée (Ve représente la vitesse d'incorporation de leucine extérieure dans le pool interne de leucine, $\mathrm{Vb}$, la vitesse de production endogène de leucine par biosynthèse, et $\mathrm{Vp}$, la vitesse de synthèse protéique).

Fig. 2. - Protein synthesis pathway including external leucine and biosynthesized leucine incorporations $(\mathrm{Ve}=$ external leucine incorporation rate in the internal leucine pool, $\mathrm{Vb}=$ endogenous production of biosynthesized leucine. $\mathrm{Vp}=$ protein synthesis rate). 
où : DPM ajoutés = quantité de leucine radioactive ajoutée exprimée en DPM

DPM incorporés $/ \mathrm{h}=$ DPM TCAf * R *60/t

$\mathrm{R}=\mathrm{DPM}$ TCAC/DPM TCAf de la première concentration

$t=$ temps d'incorporation.

La relation est bien vérifiée à PetitSaut (fig. 3).

Production carbonée obtenue par l'application des facteurs de conversion: La production cellulaire à partir des incorporations de thymidine est obtenue en appliquant un facteur de conversion théorique : $1.10^{18}$ cellules produites par mole de thymidine in- corporée dans l'ADN. Cette production cellulaire doit être multipliée par la biomasse carbonée individuelle pour obtenir la production carbonée en fentog de carbone $\left(10^{-15} \mathrm{~g}\right.$ de carbone) produits/l.h.

En ce qui concerne la leucine, la production carbonée peut être obtenue directement en appliquant un des facteurs de conversion théoriques suivant:

$1545 \mathrm{gC} / \mathrm{mole}$ de leucine incorporée dans les protéines (Simon et Azam, 1989) ;

$1080 \mathrm{gC} / \mathrm{mole}$ de leucine incorporée dans les protéines (Servais et Lavandier, 1993).

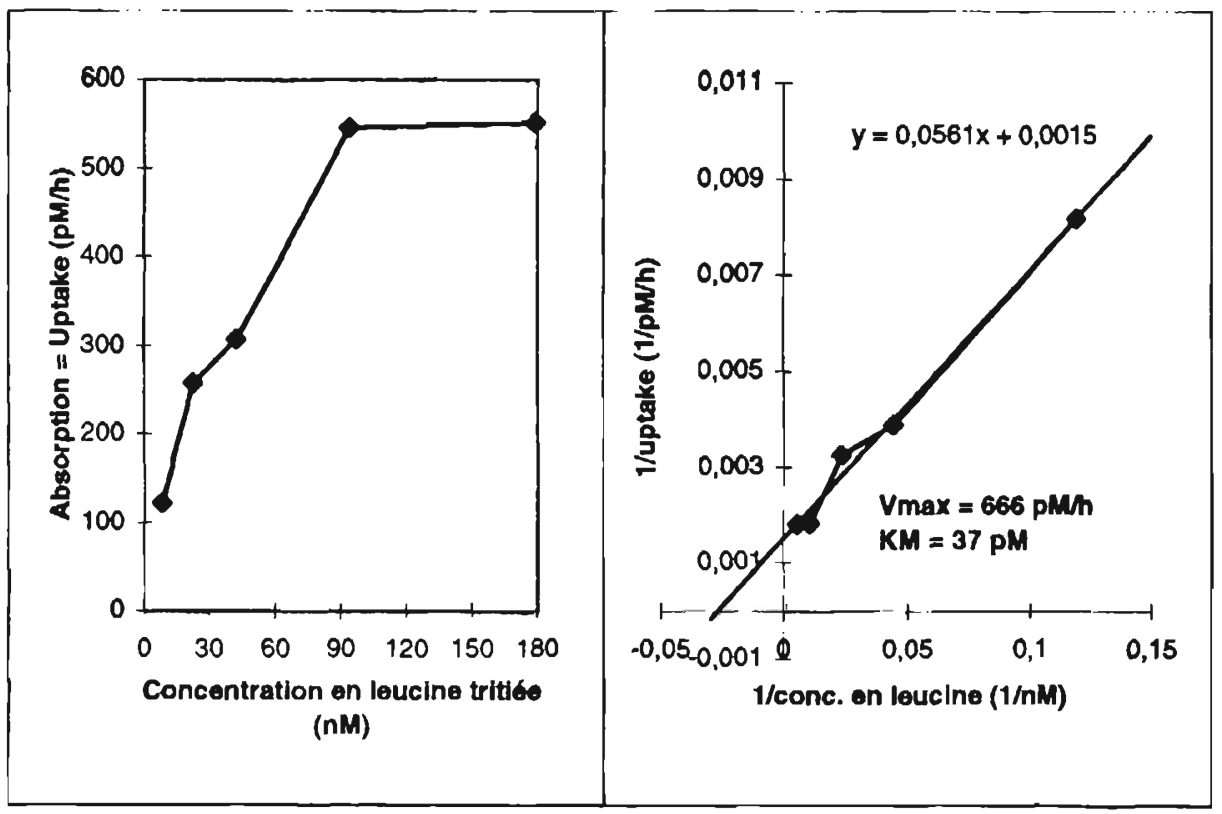

Fig. 3. - Exemple de cinétique d'absorption de la leucine tritiée à Petit-Saut (Station BPS, $-1 \mathrm{~m}$.) Fig. 3. - An example of the kinetics of tritiated leucine absorption in Petit-Saut lake (BPS, $-1 \mathrm{~m}$ ). 
Un facteur de conversion expérimental sera déterminé par la suite, mais ceci étant très lourd à mettre en œuvre, nous utiliserons le facteur théorique proposé par Servais et Lavandier (op. cité).

Les déterminations de la biomasse carbonée et de la production permettent de calculer le rapport biomasse carbonée/production carbonée qui est égal au temps de renouvellement de la population bactérienne en heures; l'inverse est égal à $\mu\left(h^{-1}\right)$ ou vitesse de croissance spécifique, caractéristique de la dynamique bactérienne globale.

\section{3 Étude des groupes physiolo- giques}

Les méthodes habituelles de numération sur milieu solide ou liquide ont été utilisées mais avec des milieux sélectifs ou des conditions d'incubations sélectives. L'activité méthanotrophique a été évaluée par des mesures de consommation de méthane puisque sa dégradation dans l'eau est uniquement biologique.

\subsubsection{Numérations sur milieu sélectif}

Les dénombrements ont été réalisés en milieu liquide en tubes et suivant la méthode d'extinction et du nombre le plus probable (MPN). La table de Mac Grady a été utilisée pour déterminer le nombre le plus probable de bactéries par dilution.

Pour dénombrer les bactéries aérobies viables, nous avons utilisé le milieu CPS de Jones (1970), addition- né de Chlorure de Triphényltétrazolium (TTC) à $10 \mathrm{mg} / \mathrm{l}$. Ceci permet une meilleure révélation des tubes positifs, le sel de tétrazolium, intercalé dans la chaîne respiratoire des bactéries, donnant une couleur rose après réduction. L'incubation dure une semaine.

Les bactéries sulfo-oxydantes aérobies sont dénombrées sur le milieu proposé par Pochon et Tardieux (1962) sous atmosphère d'air et $\mathrm{d}^{\prime} \mathrm{H}_{2} \mathrm{~S}$. L'incubation dure 20 jours.

Les bactéries méthanotrophes sont dénombrées par la méthode MPN, sur milieu ATCC (dérivé du milieu NMS, Whittenbury, 1970), additionné de TTC pour révéler les tubes positifs, et sous atmosphère de $\mathrm{CH}_{4}$ et d'air $(50 \% / 50 \%)$, à $30^{\circ} \mathrm{C}$. L'incubation dure deux mois. Des enrichissements ont été effectués à partir d'échantillons d'eau de l'oxycline congelés $\left(-20^{\circ} \mathrm{C}\right)$ après addition de $10 \%$ de glycérol. Après élimination du glycérol (trois centrifugations dans du milieu de Whittenbury), les échantillons sont cultivés dans ce même milieu sous une atmosphère contenant $50 \%$ d'air et $50 \%$ de méthane.

Nous avons testé plusieurs milieux pour dénombrer les bactéries anaérobies telles que les sulfo-oxydantes phototrophes, les sulfato-réductrices (Pochon et Tardieux, 1962) et les anaérobies totales (Brewer, 1942). Cependant, pour de telles cultures, il serait nécessaire de travailler en conditions anaérobies strictes, sous cloche stérile et en atmosphère anoxygénique que nous n'avons pu réaliser à Petit-Saut. 


\subsubsection{Evaluation de l'activité des bactéries méthanotrophes}

\section{Consommation potentielle de mé- thane}

Cette expérience avait pour but de constituer un profil de consommation de méthane sans limitation de substrats $\left(\mathrm{CH}_{4}\right.$ et $\left.\mathrm{O}_{2}\right)$. Cette consommation était donc uniquement fonction de la biomasse des méthanotrophes actifs présents dans le milieu.

Pour chaque profondeur, $40 \mathrm{ml}$ de milieu ont été prélevés, saturés en oxygène et placés dans un flacon de $146 \mathrm{ml}$, qui est ensuite bouché par un septum et serti. Un volume adéquat de méthane pur $(10 \mathrm{ml})$ est injecté dans le flacon. Après une vigoureuse agitation, la concentration dans le "headspace" est dosée par CPG. L'application de la Loi de Henry (Mackay et Shiu, 1981) nous permet de connaitre la quantité totale de $\mathrm{CH}_{4}$ présente dans le flacon à to. Un témoin est réalisé avec de l'eau distillée.

La quantité de $\mathrm{CH}_{4}$ ajoutée permet d'obtenir une concentration dans la phase aqueuse (environ $2 \mathrm{mg} / \mathrm{l}$ ) supérieure à ce qui est mesuré in situ dans la zone aérobie; nous considérons que cette quantité est saturante. Les témoins montrent qu'il n'y a pas de perte abiotique de méthane jusqu'à $24 \mathrm{~h}$.

Les flacons sont mis à incuber une heure dans les conditions du milieu naturel. Un second dosage dans le "headspace " est alors réalisé. La vitesse de consommation potentielle de $\mathrm{CH}_{4}$ est obtenue par la différence des deux mesures ramenée au litre et à l'heure.

\section{Consommation réelle de méthane}

En vue d'établir le bilan de méthane dans la colonne d'eau, nous avons mesuré la vitesse d'oxydation du méthane dans la zone aérobie. Peu de travaux mettent en évidence ce phénomène dans des conditions proches de celles de Petit-Saut. Des études poussées ont été réalisées sur des lacs naturels canadiens en période de stratification (Experimental Lakes Area) par Rudd et al. (1974, $1975,1976)$. Ils ont obtenu leurs mesures grâce à un dispositif expérimental très lourd d'utilisation et faisant intervenir du méthane radioactif. Dans l'impossibilité actuelle de faire de même à Petit-Saut, nous avons opté pour un protocole plus simple, inspiré de celui de Jannasch (1975) sur le Lac Kivu, lac stratifié salé d'Afrique centrale.

Toutes les mesures ont été réalisées le 16/12/95 au niveau de la barge installée sur l'ancien lit du fleuve en amont du barrage (station BPS). La profondeur maximale était de $32,5 \mathrm{~m}$.

La consommation de méthane dans les conditions "in situ" fut mesurée de la façon suivante:

Des flacons en verre de $26 \mathrm{ml}$, bouchés par un septum et sertis, ont été totalement remplis par de l'eau prélevée à la seringue en amont de la tête de pompe péristaltique. Une aiguille piquée au sommet de flacon permet d'évacuer le surplus d'eau injectée. Nous avons fait circuler $60 \mathrm{ml}$ 
d'eau dans le flacon. Le dosage du $\mathrm{CH}_{4}$ dans deux flacons ainsi préparés, juste après leur remplissage, permet d'estimer la perte de $\mathrm{CH}_{4}$ lors e la manipulation. Ce dosage se fait en prélevant rapidement $20 \mathrm{ml}$ au fond du flacon tout en laissant entrer l'air ambiant par une aiguille piquée au sommet. Ces $20 \mathrm{ml}$ ont été ensuite injectés dans un flacon de $57 \mathrm{ml}$ à bouchon téfloné, serti et sous vide, ce qui permet l'analyse ultérieure par CPG.

Les flacons "essais" ont été laissés $1 \mathrm{~h}$ dans les conditions du milieu, puis prélevés comme énoncé ci-dessus. La vitesse de consommation de méthane, en $\mathrm{mg}$ de $\mathrm{CH}_{4} / \mathrm{l}$.h, a été obtenue par différence des concentrations mesurées après $1 \mathrm{~h}$ d'incubation.

\subsection{Mesures diverses}

\subsubsection{Mesures "in situ»}

L'oxygène dissous, le $\mathrm{pH}$, le Eh et la température ont été mesurés grâce des appareils de terrain WTW. La transparence a été évaluée par la méthode du disque de Secchi.

\subsubsection{Dosage des sulfures totaux}

Nous avons mis au point un protocole simple de dosage des sulfures totaux dans la colonne d'eau du lac, afin de réaliser des profils de concentration et de suivre leur évolution au cours du temps.

Nous avons opté pour la méthode colorimétrique de Cline (1969) qui s'avère être peu coûteuse et d'une précision satisfaisante, étant données les fortes concentrations présentes à Petit-Saut. Cependant, nous l'avons adaptée à notre mode de prélèvement par pompe péristaltique, pour limiter les pertes et minimiser le contact avec l'oxygène.

La pompe péristaltique permet de prélever l'eau à différentes profondeurs et de réaliser des profils relativement fins dans la colonne d'eau. Le prélèvement est réalisé au travers d'un septum en amont de la tête de pompe grâce à une seringue en plastique de $60 \mathrm{ml}$. La seringue est remplie de $2 \mathrm{ml} \mathrm{d} \mathrm{HCl} 5,93 \mathrm{M}$, puis de $48 \mathrm{ml}$ de milieu naturel. Cette opération a pour but de dissocier les sulfures métalliques. A ce $\mathrm{pH}$, proche de 1 , les sulfures sont sous la forme $\mathrm{SH}_{2}$. Nous laissons agir 15 minutes, puis $10 \mathrm{ml}$ d'acétate de zinc à $2 \%$ sont ajoutés, ce qui permet de fixer les sulfures pour limiter les pertes (les sulfures de zinc sont insolubles). Le tout peut être stocké au frais pendant quelques heures jusqu'à l'analyse.

Le dosage colorimétrique s'effectue par adjonction de NN-diéthyl-p-phénylènediamine et de $\mathrm{NH}_{4} \mathrm{Fe}\left(\mathrm{SO}_{4}\right)_{2}$.

L'absorbance des solutions est mesurée à $670 \mathrm{~nm}$ de longueur d'onde par un spectrophotomètre Milton Roy de type Spectronic 401, dans une cuve de $5 \mathrm{~cm}$ pour les faibles concentrations ou dans une cuve de $1 \mathrm{~cm}$ pour les plus fortes. Les étalons sont préparés dans des flacons de Winkler en verre parfaitement propres, à partir d'une solution aqueuse désoxygénée de $\mathrm{Na}_{2} \mathrm{~S}$. 
La limite de détection est de l'ordre de $0,3 \mu \mathrm{M}(9,6 \mu \mathrm{g} / \mathrm{l})$, ce qui est tout à fait acceptable ici puisque les concentrations observées sont nettement supérieures sur la majeure partie de la colonne d'eau.

\section{RÉSULTATS ET DISCUSSIONS}

\subsection{Populations, biovolumes et biomasses bactériennes totales}

\subsubsection{La colonne d'eau du lac}

Profils de numération en épifluorescence

Les profils de la figure 4 représentent les résultats obtenus au cours de l'année 1995. En février, le profil d'abondance est relativement uniforme sur la colonne d'eau, avec un maximum de bactéries dans les 5 premiers mètres $\left(9.10^{6} \beta / \mathrm{ml}\right)$. Dans les mois suivants, nous avons vu apparaître et croître un pic d'abondance bactérienne sous l'oxycline. II atteignait $16.10^{6} \mathrm{\beta} / \mathrm{ml}$ en mai et $23.10^{6} \mathrm{\beta} / \mathrm{ml}$ en septembre. Au mois de décembre, on note encore une augmentation mais moindre de ce pic $\left(25.10^{6} \beta / \mathrm{ml}\right)$. II semblerait que ces populations bactériennes atteignent peu à peu un plateau, la croissance la plus forte ayant été observée entre février et septembre 1995.

$\mathrm{Ce}$ pic a tendance à s'enfoncer dans la colonne d'eau corrélativement à l'enfoncement de l'oxycline et à l'approfondissement de la zone euphotique.
Les bactéries présentes à ce niveau sont donc anaérobies et probablement des sulfo-oxydantes phototrophes.

On note, de même, une constante augmentation des populations aérobies depuis le début du suivi, avec aussi un début de stabilisation en décembre. Ceci est probablement lié à une régulation de la croissance bactérienne par le substrat qui devient limitant dans les deux cas.

Les valeurs obtenues classent le lac dans les plans d'eau eutrophes si on le compare aux lacs de barrage étudiés au laboratoire (tab. I).

Les populations profondes anaérobies étaient relativement constantes de février à septembre $\left(6-7.10^{6} \mathrm{~B} / \mathrm{ml}\right)$ puis ont montré une nette augmentation en décembre $\left(10.10^{6}[3 / \mathrm{ml})\right.$. Cette croissance a été stimulée probablement par un nouvel apport de matière organique, provenant de la forte

Tableau I. - Comparaison de l'abondance bactérienne à Petit-Saut avec celles de quelques lacs tempérés ou froids étudiés au laboratoire ("Petit, Lavandier. Communication personnelle).

Table I. - A comparison between bacterial abundance at Petit-Saut and the abundance measured in cold or temperate lakes studied in our laboratory (" Petit, Lavandier. Personal communication).

$\begin{array}{cc}\text { Niveau trophique } & \begin{array}{c}10^{+6} \text { bacté- } \\ \text { ries/ml }\end{array} \\ \text { Lac hyper-eutrophe (Layrac) : } & 25-35^{*} \\ \text { PS zone intermédiaire } & 16-24 \\ \text { PS zone aérobie } & 6-16 \\ \text { Lac mésotrophe (Pareloup) } & 3-8^{*} \\ \text { PS anaérobie } & 5-8 \\ \text { Lac oligotrophe (Orédon) } & 1-2^{*}\end{array}$




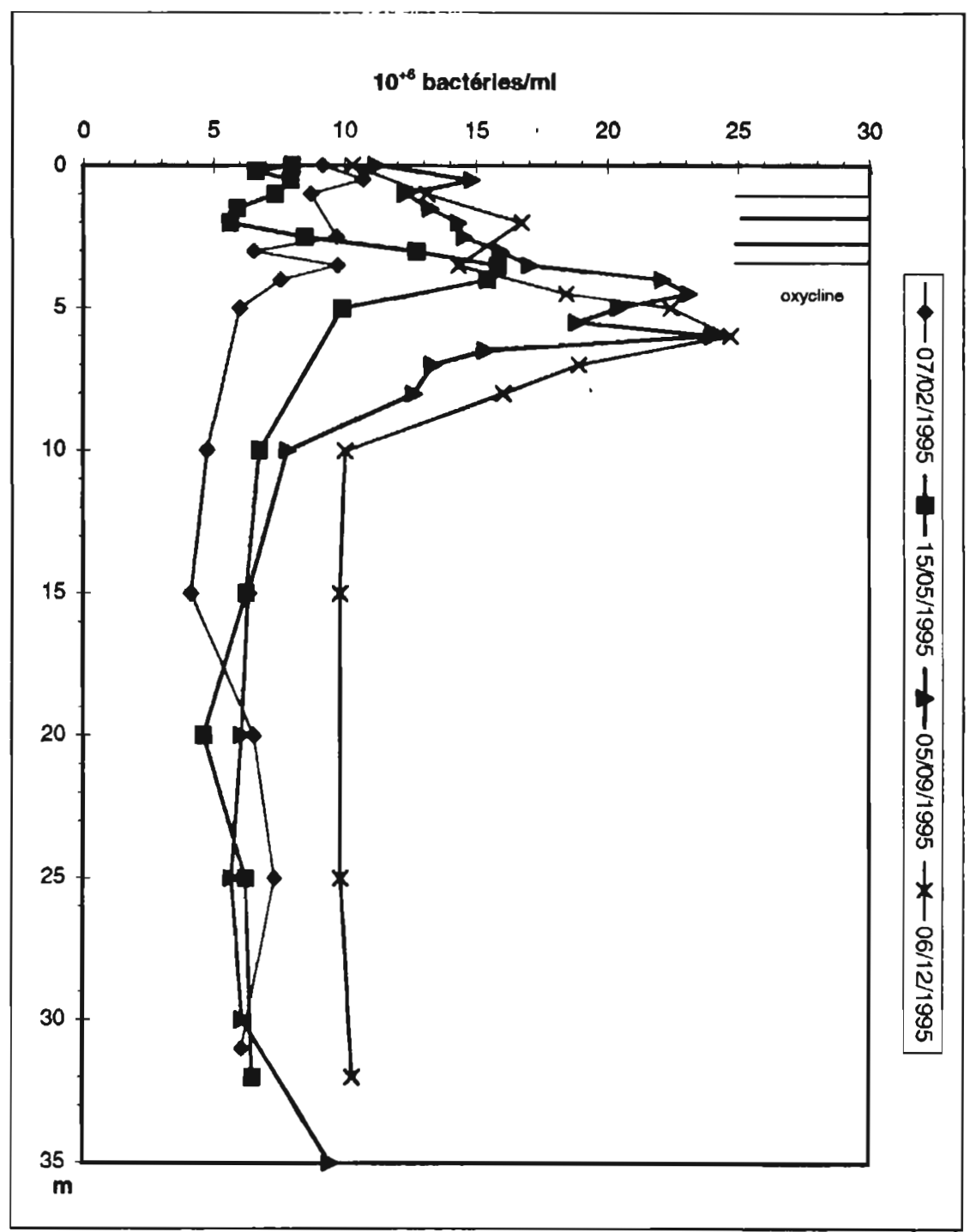

Fig. 4. - Evolution de l'abondance bactérienne dans la colonne d'eau du lac de Petit-Saut, à la station BPS, en 1995.

Fig. 4. - Fluctuations of bacterial abundance in Petit-Saut water column, BPS, 1995. 
production des couches de surface (algues, bactéries phototrophes et hétérotrophes, zooplancton) ou d'une forte crue survenue pendant cette période.

Un profil a été réalisé en forêt inondée le 08/09/95. L'oxycline se situait à $3 \mathrm{~m}$ de profondeur. Par rapport à la station BPS, l'abondance bactérienne était nettement plus forte en zone aérobie. Par contre, le pic sous l'oxycline était beaucoup moins prononcé. Nous avons ici affaire à une autre distribution des populations bactériennes, le milieu étant plus riche en matière organique et la lumière pénètrant moins profondément dans la colonne d'eau.

Dénombrements sur milieux synthétiques

En ce qui concerne les bactéries anaérobies, les dénombrements n'ont donné aucun résultat interprétable. Soit aucune croissance n'a été observée, soit des problèmes de contamination sont intervenus. En effet, il nous a été difficile de maintenir des conditions d'anaérobiose dans les tubes.

Nous n'avons donc pas pu mettre en évidence de cette façon les groupes bactériens tels que les sulfooxydants phototrophes ou les sulfatoréducteurs.

De même, aucun sulfo-oxydant aérobie n'a été dénombré à BPS.

La flore aérobie totale a èté dénombrée sur le milieu CPS de Jones qui semble bien convenir aux bactéries de ce milieu. La "réponse" est maximale au niveau de l'oxycline. Ici, le dénombrement correspond à peu près à la numération en épifluorescence, ce qui est exceptionnel. En zone aérobie, le dénombrement correspond à environ $5 \%$ de la numération au DAPI, ce qui est plus fréquent. La "cultivabilité" nous donne une première indication sur l'état physiologique des bactéries aérobies. Elles sont apparemment en pleine activité à l'oxycline et en activité plus réduite au-dessus.

Les incubations pour dénombrer les bactéries méthanotrophes ont aussi échoué. Par contre, les enrichissements ont montré que les échantillons prélevés à l'oxycline donnaient naissance à des populations de plus en plus nombreuses entre février et décembre 1995 (fig. 5). II faut cependant noter qu'il s'agit de consortium, les métanotrophes nourrissant de nombreux commensaux par des excrétions de méthanol (Houbron, 1995).

Par la suite, nous avons entrepris d'utiliser une méthode de reperage biochimique des groupes physiologiques. En effet, il est possible de doser apres extraction avec des solvants, les lipides bactériens spécifiques de chaque groupe. Cette technique donne de bons résultats pour les bactéries méthanotrophes, sulfo-oxydantes et sulfato-réductrices. Les premiers résultats obtenus avec les méthanotrophes sont encourageants.

\section{Biovolumes}

Nous avons déterminé les biovolumes des populations bactériennes présentes à BPS à $-1 \mathrm{~m},-4,5 \mathrm{~m}$, $-7 \mathrm{~m}$ et $-15 \mathrm{~m}$ de profondeur, le $19 / 12 / 95$. Pour chaque profondeur, les 


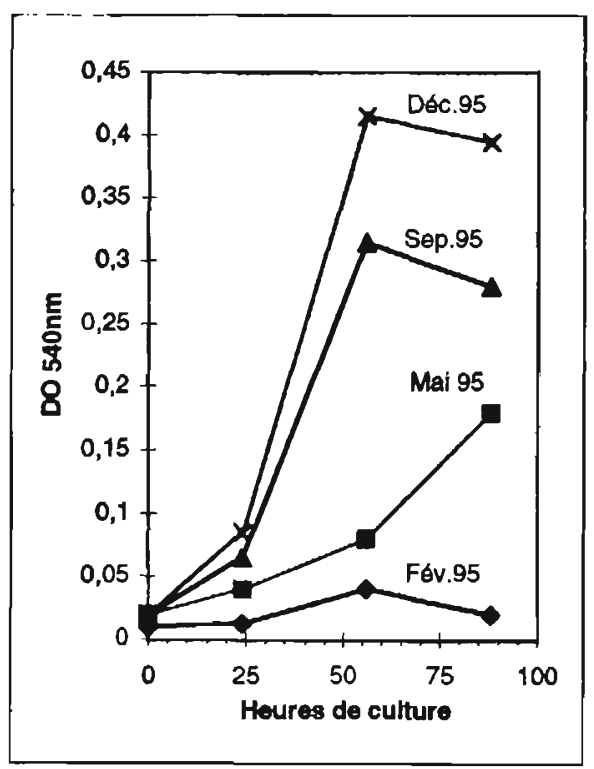

Fig. 5. - Evolution de la biomasse (DO à $540 \mathrm{~nm}$ ) lors de l'enrichissement en méthanotrophes d'échantillons d'eau prélevés à l'oxycline lors des 4 campagnes de 1995.

Fig. 5. - Biomass variations (Optical density measured at $540 \mathrm{~nm}$ ) during methanotrophic bacterial enrichments of water samples taken at the oxicline level for the four campaigns, 1995.

populations sont relativement hétérogènes et les biovolumes cellulaires varient de $0,0023 \mu \mathrm{m}^{3}$ à $0,62 \mu \mathrm{m}^{3}$. Cependant, ce sont des bactéries de très petite taille qui prédominent. Le biovolume individuel moyen est maximal à l'oxycline $\left(0,0494, \mathrm{~mm}^{3} / \beta\right)$ et minimal à $-15 \mathrm{~m}\left(0,0318 \mu \mathrm{m}^{3} / \beta\right)$.

\section{Biomasses carbonées}

Aux mêmes profondeurs, nous avons calculé la biomasse carbonée bactérienne par $\mathrm{ml}$ d'eau. La biomasse carbonée totale est élevée à $-4,5 \mathrm{~m}\left(18.10^{7} \mathrm{fgC} / \mathrm{ml}\right)$ et à $-7 \mathrm{~m}$ $\left(16.10^{7} \mathrm{fgC} / \mathrm{ml}\right)$. Cette biomasse est nettement plus faible en profondeur $\left(4,7 \cdot 10^{7} \mathrm{~g} \mathrm{gC} / \mathrm{ml}\right)$.

\subsubsection{Le fleuve en aval du barrage}

La figure 6 représente le suivi des bactéries totales depuis février 1995. Le nombre de bactéries présentes en aval à la sortie des turbines est toujours plus élevé que la quantité de bactéries présentes à - $10 \mathrm{~m}$ dans la colonne d'eau. L'eau turbinée provient donc d'un panache entraînant des bactéries profondes anaérobies mais aussi des bactéries du sommet de la colonne d'eau, telles les sulfo-oxydantes anaérobies présentes entre $-5 \mathrm{~m}$ et $-7 \mathrm{~m}$ (cf. Vaquer, ce volume) et probablement des bactéries méthanotrophes puisqu'elles se situent immédiatement au-dessus. La consommation de méthane dans le fleuve confirme ce point de vue.

Les numérations montrent une augmentation du nombre de bactéries tout le long du fleuve, jusqu'à PointeCombi. Celte augmentation, sur un plan spatial, se fait aussi sur un plan diachronique, puisque, à chaque station, le nombre de bactéries augmente de février à décembre. On note cependant que cette augmentation se fait irrégulièrement, avec des périodes de diminution. Ces variations sont à mettre en rapport avec les variations de débits de sortie du barrage qui déterminent le temps de séjour des bactéries en suspension.

II y a donc une acclimatation rapide des bactéries relarguées par le bar- 


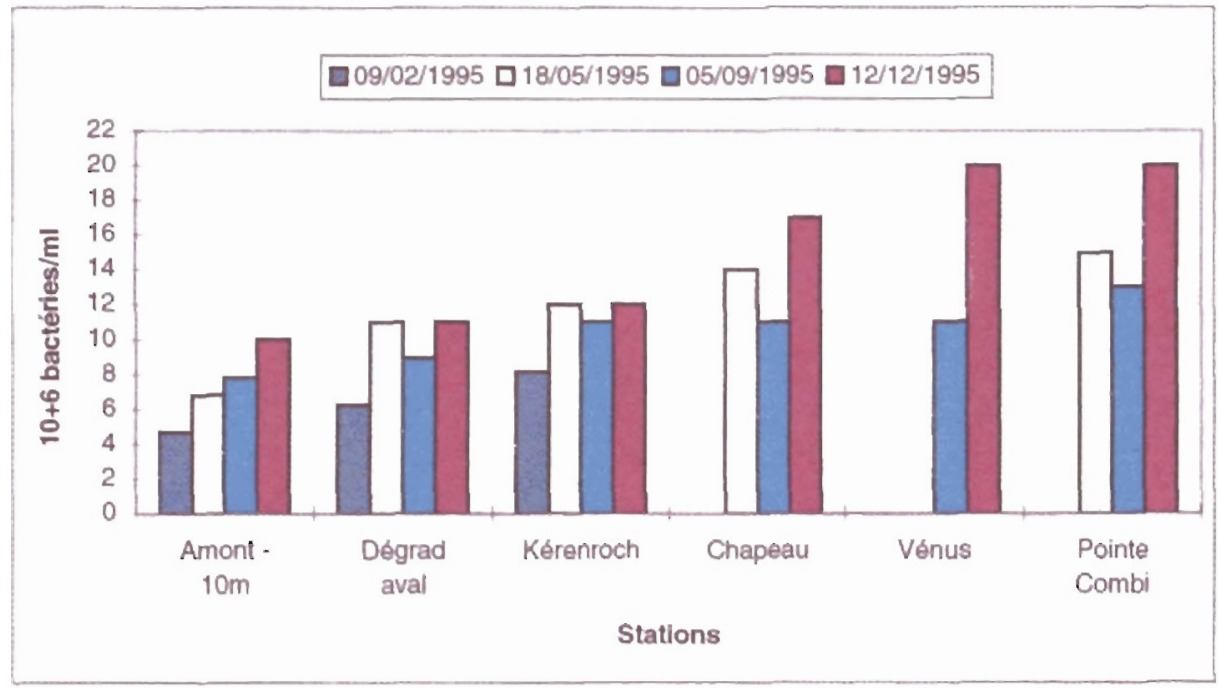

Fig. 6. - Evolution de l'abondance bacterienne dans le fleuve Sinnamary, en aval du barrage, au cours de l'annèe 1995.

Fig. 6. - Fluctuations of bacterial abundance in the Sinnamary River, downstream of the dam. during 1995.

rage dans le fleuve aval où se produit un mélange d'eaux aux caractéristiques physico-chimiques très différentes.

\subsection{Production de biomasse}

\subsubsection{Taux moyen de division cel- Iulaire}

Les soins apportés à l'expérience de décembre, réalisée in situ, nous ont permis d'obtenir des résultats probablement plus représentatifs de la réalité que les résultats précédents.

A $-1 \mathrm{~m}$ de profondeur, $R=0,016 h^{-1} ; \dot{a}-4,5 m, R=0,020 h^{-1}$; à $-7 \mathrm{~m}, \mathrm{R}=0,0032 \mathrm{~h}^{-1}$; à $-15 \mathrm{~m}$, $R=0,0019 h^{-1}$. Les taux moyens de division sont environ dix fois plus forts pour les populations aérobies que pour les population anaérobies, ce qui n'est pas surprenant. De plus, les populations à l'oxycline possèdent le taux de division spécifique le plus fort $\left(0,02 \mathrm{~h}^{-1}\right)$, significatif d'une activité intense.

\subsubsection{Production carbonée hétéro- trophe}

Incorporation de thymidine ${ }^{3} \mathrm{H}$

Les incorporations de thymidine- ${ }^{3} \mathrm{H}$ en fonction de la concentration ajoutée donnent des résultats peu cohérents, autant à $-1 \mathrm{~m}$ qu'à $-15 \mathrm{~m}$ de profondeur.

Les incorporations sont du même ordre de grandeur qu'en mai et, de la même façon, il est impossible de traiter les courbes obtenues pour déter- 
miner des constantes de 1/2 saturation $\left(\mathrm{K}_{\mathrm{m}}\right)$ et des vitesses d'incorporation maximale. Ceci confirme le fait que la méthode à la thymidine n'est pas applicable dans nos conditions opératoires à Petit-Saut. Ceci n'est pas surprenant en anaérobiose, car des études ont montré que des bactéries anaérobies telles les sulfatoréductrices n'incorporent pas la thymidine (Winding, 1992). En aérobiose, ceci est plus étonnant et il nous est pour l'instant impossible de savoir pourquoi les incorporations de thymidine $-{ }^{3} \mathrm{H}$ ne se font pas de la façon observée sur des lacs tempérés ou froids (Pareloup, Aveyron - Layrac, Tarn - Orédon, Pyrénées). Une hypothèse serait que l'activité de synthèse de l'ADN est très élevée par rapport aux lacs tempérés, à tel point que l'absorption membranaire est saturée et ne permet pas d'inhiber la synthèse de novo de thymidine. Par contre, le profil réalisé avec une concentration arbitraire de 142 nM semble cohérent et rappelle les profils obtenus avec la leucine.

Nous préférons donc laisser cette méthode de côté et utiliser les incorporations de leucine.

\section{Incorporations de leucine ${ }^{3} \mathrm{H}$}

Les droites de régressions obtenues d'après les incorporations de leucine- ${ }^{3} \mathrm{H}$ sont tout à fait satisfaisantes (cf. fig. 3).

Un profil d'incorporation a été réalisé à la station BPS (fig. 7). Les valeurs d'incorporations vont de $13,6 \mathrm{pmoles} / \mathrm{l}$.h à $-15 \mathrm{~m}$ à 247 pmoles/l.h à $-4,5 \mathrm{~m}$. Ce large éventail est tout à fait normal puisqu'on sait que les bactéries anaérobies ont en général une activité d'incorporation beaucoup plus faible que les aérobies. Ici l'activité aérobie est environ 3 à 20 fois plus forte que l'activité anaérobie. Les incorporations maximales sont obtenues à l'oxycline (247 pmoles/l.h), confirmant une forte activité bactérienne à ce niveau. Nous verrons que l'activité des méthanotrophes est aussi maximale à ce même niveau.

Si l'on compare ces résultats avec ceux des lacs de différents niveaux trophiques, on s'aperçoit que la partie aérobie de Petit-Saut correspond, suivant ces critères de production bactérienne, à un lac eutrophe, voire hyper-eutrophe (tab. II).

Tableau II. - Vitesses d'incorporation de leucine à Petit-Saut comparée à celles de lacs tempérés ou froids étudiés au laboratoire ("Petit, Lavandier. Communication personnelle). Table II. - Leucine incorporation rates at Petit-Saut compared with those measured in cold or temperate lakes (* Petit, Lavandier. Personal communication).

Lac

Layrac (fév. 95)

PS aérobiose (déc. 95)

Pareloup (juil. 95)

PS anaérobiose (déc. 95)

Orédon (sep. 95)

\section{Niveau trophique}

hyper-eutrophe

mésotrophe

oligotrophe

\section{V (pmoles/l.h)}

150 à $1000^{*}$

106 à 247

3 à $80^{*}$

13 à 40

4 à $13^{*}$ 


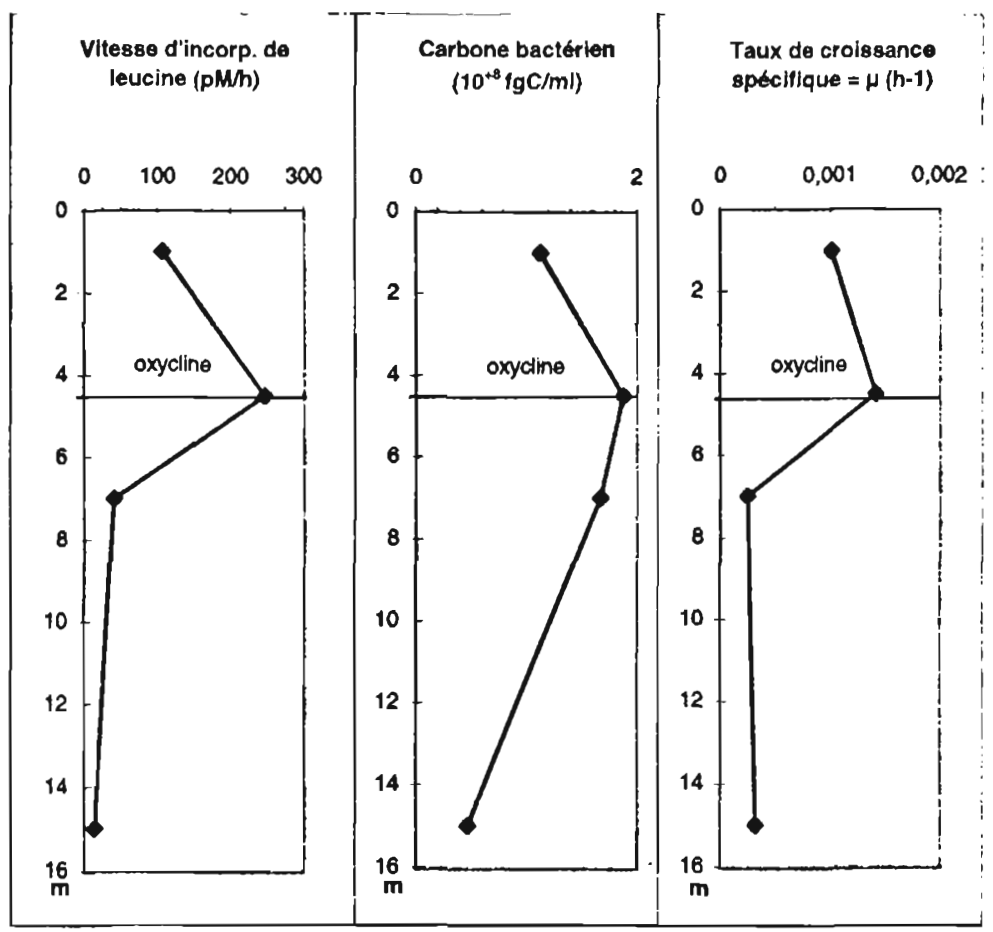

Fig. 7. - Profils de vitesse d'incorporation de leucine, de biomasse bactérienne et de taux de croissance spécifique à la station BPS en septembre 1995.

Fig. 7. - Leucine incorporation rates, bacterial biomass and specific growth rate profiles. BPS, during September 1995.

Il est également intéressant de noter que, malgré une biomasse carbonée équivalente à celle de l'oxycline, les populations de $-7 \mathrm{~m}$ de profondeur ont une activité d'incorporation 6 fois plus faible. Bien entendu, les taux de croissance calculés en aérobiose $\left(0,00101 h^{-1}\right.$ à $\left.0,00142 h^{-1}\right)$ sont de 3 à 6 fois supérieurs à ceux observés en zone anaérobie 10,00025 à $\left.0,00315 h^{-1}\right)$. Ceci est normal car pour un même substrat, des bactéries anaérobies ont une production énergétique 19 fois moins rentable et une assimilation 6 fois plus faible que des bactéries aérobies ( $F$. Edeline, 1993).

Pour la zone aérobie, les taux de croissance $\mu$ ne sont pas supérieurs à ceux mesurés à Pareloup en zone tempérée $\left(0,00046\right.$ à $\left.0.00166 \mathrm{~h}^{-1}\right), \mathrm{du}$ fait d'une biomasse plus élevée. 
Une comparaison peut être faite entre les taux de croissance spécifiques obtenus par incorporation de leucine et les résultats obtenus en mesurant le taux moyens de division cellulaire $\mathrm{R}$ par un accroissement du nombre de bactéries. Pour $-1 \mathrm{~m}$, $-4,5 \mathrm{~m}$ et $-7 \mathrm{~m}$ de profondeur, le taux de croissance $\mu$ est inférieur à $\mathrm{R}$ d'environ un facteur 15 ; tandis que pour le point réalisé à $-15 \mathrm{~m}$, le rapport $R / \mu$ atteint une valeur proche de 6 .

Une telle différence a déjà été observée dans les lacs tempérés eutrophes (Couturier, 1995). Peut-être est-elle liée à l'importance de la synthèse de leucine de novo en présence d'une concentration élevée en ammonium.

\subsection{Activité des groupes physio- logiques}

\subsubsection{Consommation potentielle de méthane}

Les profils d'oxygène et de méthane dissous ainsi que la vitesse de consommation de $\mathrm{CH}_{4}$ au 12/09/95, en fonction de la profondeur, sont représentés sur la figure 8.

Le profil d' $\mathrm{O}_{2}$ indique la présence d'une oxycline entre $-2 m$ et $-3 m$ de profondeur. Une forte chute de la concentration en méthane est également mesurée à ce niveau. La consommation potentielle de $\mathrm{CH}_{4}$ semble être relativement stable de 0 à $-2 \mathrm{~m}$ (environ $6 \mathrm{mg} \mathrm{CH} / /$.h). Au niveau de l'oxycline, la consommation observée est maximale $(11,6 \mathrm{mg}$ $\mathrm{CH}_{4} / \mathrm{l}$.h) et elle tend à s'annuler à partir de $-3 \mathrm{~m}$.
Ces résultats confirment la première approche de repérage des méthanotrophes par enrichissement d'échantillons d'eau : ils sont présents dans toute la partie oxygénée de la colonne d'eau avec un pic d'abondance au niveau de l'oxycline.

Les vitesses d'oxydation mesurées sont extrêmement fortes, ce qui dénote la présence d'une population méthanotrophe dense et/ou très active.

\subsubsection{Consommation réelle de méthane}

Les résultats obtenus sont représentés sur la figure 9. Le profil d'oxygène dissous met en évidence une oxycline dans les 5 premiers mètres. La concentration en méthane chute considérablement à la base de cette oxycline. Par contre, le $\mathrm{pH}$ et la température ne subissent pas de variations à ce niveau.

La consommation de $\mathrm{CH}_{4}$ est réalisée à presque $100 \%$ à $-4 \mathrm{~m}$ de profondeur et la vitesse d'oxydation mesurée à $-4,5 \mathrm{~m}$ est de $0,275 \mathrm{mg} / \mathrm{l} . \mathrm{h}$.

Cette vitesse est cent fois supérieure aux valeurs obtenues par Rudd et al. (1974) sur le lac 120 (ELA) ou par Jannasch (1975) sur le lac Kivu (tab. III).

Plusieurs faits sont à la base d'une telle différence. En ce qui concerne les lacs canadiens, ces lacs sont beaucoup plus froids que Petit Saut (de 14 à $5^{\circ} \mathrm{C}$ à l'oxycline). D'autre part, le développement des bactéries méthanotrophes est lié à la fixation d'azote diatomique car les eaux sont 


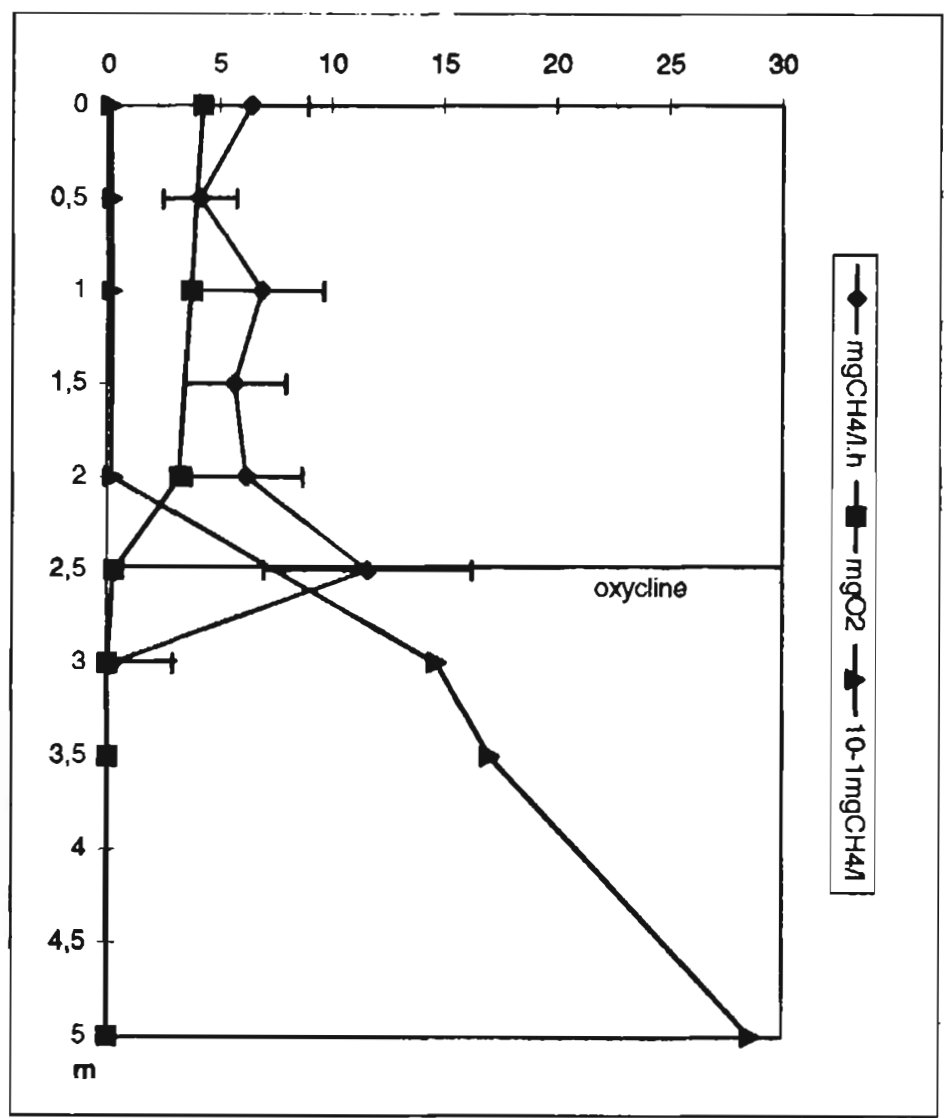

Fig. 8. - Evolution de la consommation potentielle de méthane en fonction des teneurs en oxygene et en méthane dans la colonne d'eau à la station BPS en septembre 1995.

Fig. 8. - Variation of potential melhane consumption with regards to dissolved oxygen and methane in the water column. BPS. on September 1995.

Tableau III. - Estimation de la consommation de méthane a l'oxycline pour trois lacs différents (" Rudd et al., 1974; " Jannasch, 1975).

Table III. - Estimated methane consumption at the oxicline level on three different lakes ("Rudd and al., 1974; "* Jannasch, 1975).

Lac

Petit Saut (déc. 95)

Lac 120*

Kivu"
C

28

5

23
$\mathrm{mgCH} 4 /$

1.6

0.07

1
mgCH4/.h

0.275

0.00224

0.0028 


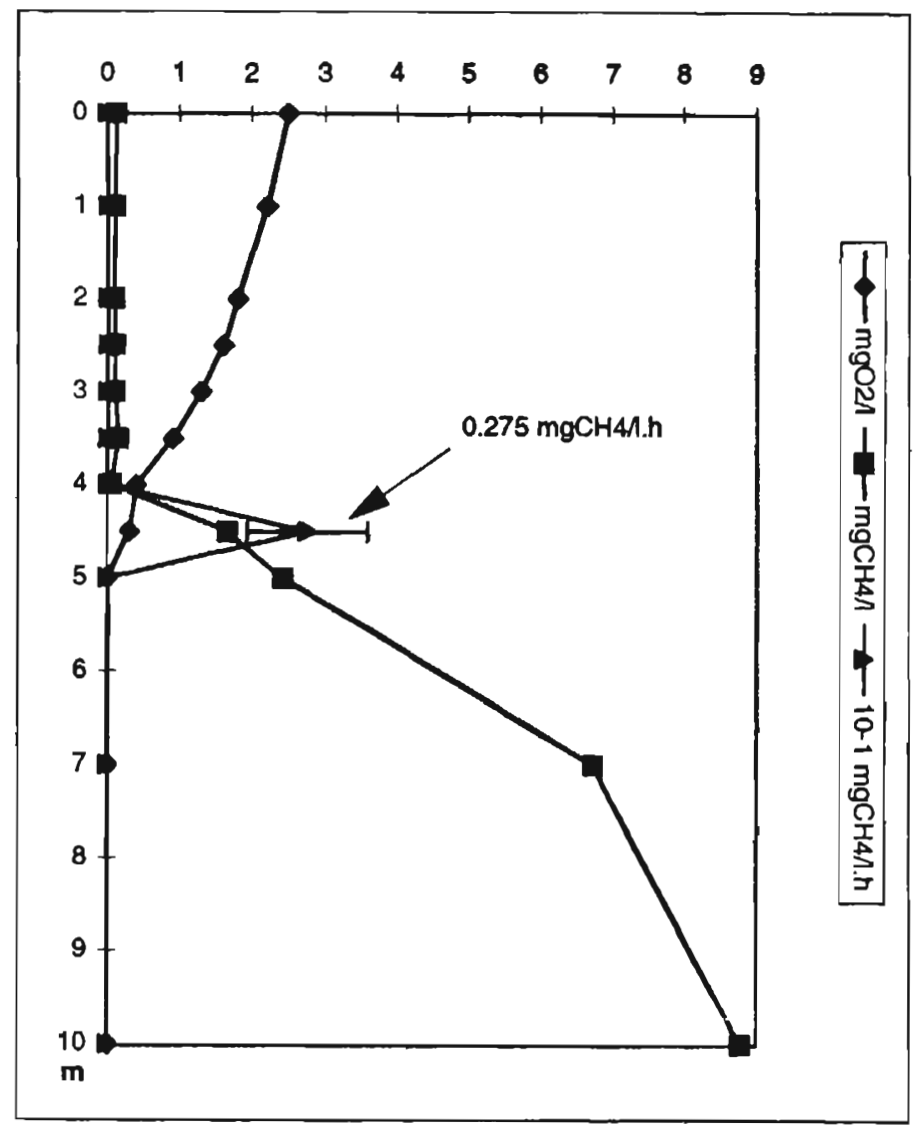

Fig. 9. - Evolution de la consommation réelle en méthane en fonction des teneurs en oxygène et en méthane à la station BPS en décembre 1995.

Fig. 9. - Variation of real methane consumption with regards to dissolved oxygen and methane, BPS, on December 1995.

pauvres en azote ammoniacal. Si l'on ajoute du chlorure d'ammonium à des cultures, leurs performances dépassent celles de Petit-Saut. De plus, au niveau de l'oxycline, la concentration en $\mathrm{CH}_{4}$ est de l'ordre de $0,07 \mathrm{mg} / \mathrm{l}$ dans le lac 120 (1,6 mg/l à Petit-Saut) et la concentration au fond est de $8,5 \mathrm{mg} / \mathrm{l}$ (15 à $17 \mathrm{mg} / \mathrm{l}$ à Petit-Saut).
La plupart de ces arguments sont sans valeur pour le Lac Kivu où la température est d'environ $23^{\circ} \mathrm{C}$ $\left(28^{\circ} \mathrm{C}\right.$ à Petit-Saut), la concentration en $\mathrm{CH}_{4}$ au fond de $280 \mathrm{mg} / \mathrm{l}$, celle à l'oxycline est de $1 \mathrm{mg} / \mathrm{l}$ alors que la consommation à ce niveau n'est que de $0,0028 \mathrm{mg} / \mathrm{l} . \mathrm{h}$. Cette vitesse est très faible par rapport à la quantité de 
méthane présente, mais il faut noter que d'autres facteurs, parfois inconnus, peuvent limiter l'activité des méthanotrophes.

En général, l'oxydation du méthane se fait sur une faible épaisseur d'eau par rapport à la profondeur du lac: sur $1 \mathrm{~m}$ dans le lac 120, 0,5 à $1 \mathrm{~m}$ environ à Petit-Saut. Cette oxydation est aussi très localisée (quelques $\mathrm{mm}$ ), lorsqu'elle s'effectue à la surface des sédiments dans les lacs non stratifiés (King \& Blackburn, 1996; Sweerts \& al., 1996). Cela s'explique par une activité très élevée qui épuise rapidement le gaz jusqu'à des concentrations inférieures aux constantes d'affinité des méthanotrophes qui sont de l'ordre de 0,8 à $2 \mu \mathrm{M}$ en milieu liquide (Joergensen et Degn, 1987). A l'inverse, la faible activité spécifique du lac Kivu entraîne un étalement du processus entre - 35 et $-50 \mathrm{~m}$ de profondeur.

D'autres éléments du milieu peuvent affecter l'oxydation biologique du méthane, comme par exemple la compétition pour l'oxygène avec d'autres organismes hétérotrophes ou même autotrophes (King \& Blackburn, 1996). Ce sont pourtant des facteurs différents quí doivent expliquer la phase de latence d'un an observée à Petit-Saut. En effet, au début de la mise en eau, les concentrations en $\mathrm{CH}_{4}$ ne cessant d'augmenter et les concentrations en $\mathrm{O}_{2}$ dissous étant suffisantes en surface, une activité méthanotrophique aurait pu rapidement s'installer. Cela n'a pas été le cas puisque cette consommation n'a été observée qu'à partir de févriermars 1995, par le biais des mesures de flux à la surface du lac. Une hypothèse envisagée est la diminution des concentrations en $\mathrm{H}_{2} \mathrm{~S}$ en-deçà d'un seuil inhibiteur.

Estimation de la consommation de méthane par les méthanotrophes dans tout le lac

Pour ce calcul, nous supposerons que :

- la surface du lac à $-4,5 \mathrm{~m}$ de profondeur est d'environ $300 \mathrm{~km}^{2}$;

- l'oxydation du méthane se fait sur une épaisseur de $1 \mathrm{~m}$ avec une vitesse maximale de $0,275 \mathrm{mgCH}_{4} /$.h au centre. La vitesse moyenne dans la zone d'oxydation $=0,275 \mathrm{mgCH}_{4} /$.h $/ 2=2,55 \mathrm{gCH}_{4} / \mathrm{m}^{3} . \mathrm{j}$;

- volume d'eau sur $1 \mathrm{~m}$ à $4,5 \mathrm{~m}$ de profondeur $=300.10^{6} \mathrm{~m}^{3}$;

- la vitesse d'oxydation est uniforme sur tout le lac.

On voit que la consommation totale calculée est alors de $765 \mathrm{tj}$.

Cette valeur est très proche de l'émission maximale calculée en février 1995 soit $800 \mathrm{tj}$. Cette proximité est probablement fortuite car dans les deux cas, les estimations reposent sur un nombre insuffisant de mesures. Pour affiner ce chiffre, il faudrait déterminer la surface exacte du lac au niveau de l'oxycline, réaliser des profils plus fins de consommation de $\mathrm{CH}_{4}$ pour déterminer l'épaisseur d'eau dans laquelle elle est réalisée et mesurer la vitesse d'oxydation en plusieurs points du lac (forêt inondée 
notamment). Néammoins, on peut admettre que les deux résultats sont comparables.

\subsubsection{Oxydation des sulfures}

Evolution des composés réduits du soufre dans le lac

Un profil a été réalisé à la station BPS lors des campagnes de mai (26/05/95), de septembre (09/09/95) et de décembre (07/12/95). Pour chaque profondeur, deux répliques ont été dosées dans la cuve de $5 \mathrm{~cm}$. Le gaz $\mathrm{H}_{2} \mathrm{~S}$ a été dosé simultanémént par l'analyseur T.R.S. du laboratoire de Petit-Saut. La figure 10 montre l'évolution similaire des concentrations en sulfures et en gaz $\mathrm{H}_{2} \mathrm{~S}$ dans la colonne d'eau. La concentration en $\mathrm{H}_{2} \mathrm{~S}$ dissous tend vers zéro au-dessus de $-10 \mathrm{~m}$, tandis que la concentration des sulfures totaux subit une forte décroissance au-dessus de $-5 \mathrm{~m}$; il en subsistait toujours une petite quantité en surface en mai 1995, tandis qu'en septembre et décembre, les valeurs données pour 0 et $-2 m$ sont inférieures à la limite de détection théorique de la méthode.

Les sulfures totaux ont pratiquement diminué de moitié entre mai et septembre. Cette forte variation peut être attribuée à plusieurs causes : une

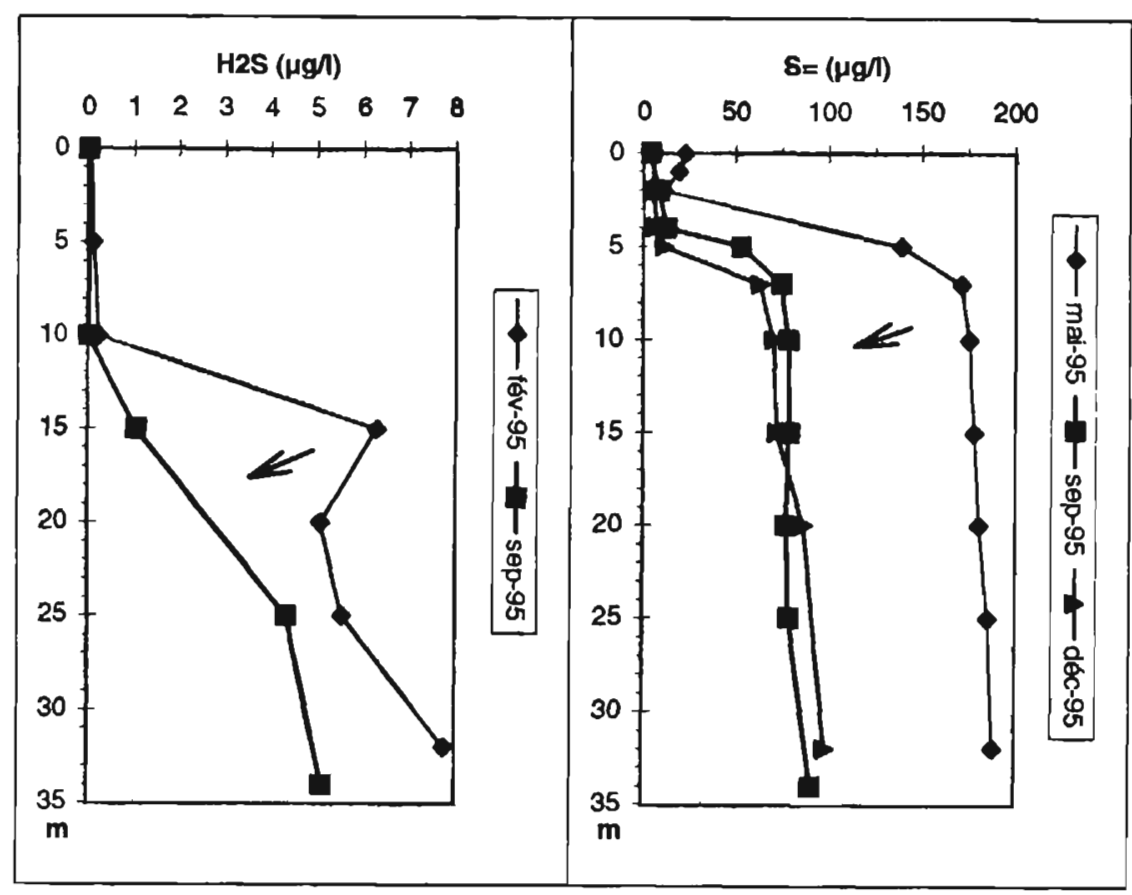

Fig. 10. - Evolution des composés réduits du soufre dans la colonne d'eau à la station BPS au cours de l'année 1995.

Fig. 10. - Fluctuations of reduced sulphur compounds in the water column, BPS, during 1995. 
forte diminution de la source (ceci paraît improbable étant donné le court laps de temps, 4 mois), une consommation élevée de la part de bactéries sulfo-oxydantes, une dilution entraînée par une forte augmentation de débit de relargage du barrage.

En effet, à partir du 10 juin, le débit relargué par le barrage qui était maintenu aux environs de $100 \mathrm{~m}^{3} / \mathrm{s}$, est passé progressivement à $750 \mathrm{~m}^{3} / \mathrm{s}$, pour revenir à sa valeur d'origine le 14 juin. Ce fort relargage a permis l'élimination massive des éléments réducteurs de la colonne d'eau, et la dilution de la quantité restante. Le suivi de la conductivité à différentes profondeurs par le laboratoire de Petit-Saut met bien en évidence ce phénomène de dilution dans les couches profondes à partir du 10 juin 1995.

Mise en évidence indirecte de bactéries sulfo-oxydantes anaérobies

La zone de forte décroissance de la concentration en sulfures dans la colonne d'eau tend à s'abaisser avec le temps. En effet, elle est passée de $-3,5 \mathrm{~m}$ de profondeur en mai à $-7 \mathrm{~m}$ en décembre (fig. 10). Cet abaissement peut être corrélé avec l'accroissement de la zone oxygénée qui est en moyenne, en décembre 1995, de $4 \mathrm{~m}$ à partir de la surface. Une oxydation chimique des sulfures y est possible. Des bactéries sulfo-oxydantes aérobies pourraient se trouver à ce niveau mais nous n'avons pu mettre en évidence ce groupe physiologique à ce niveau de la colonne d'eau.

Par contre, les comptages en épifluorescence mettent en évidence un pic d'abondance bactérienne qui se superpose à la zone de régression des sulfures sous l'oxycline (fig. 11). De plus, cette zone correspond à une grande abondance de pigment bactérien encore indéterminé (Vaquer, communication personnelle). Vaquer indique qu'il a isolé en grande quantité un piqment "Chlorobium like", donc proche de celui des bactéries sulfo-oxydantes vertes. Si les bactéries correspondantes n'ont pu être cultivées dans les deux laboratoires intéressés, il n'en demeure pas moins qu'il existe une corrélation entre l'apparition du pic de biomasse et la diminution des sulfures sous l'oxycline.

\section{Evolution des sulfures dans le Sinna- mary}

Dans la retenue, les sulfures totaux sont environ dix fois plus concentrés que $\mathrm{H}_{2} \mathrm{~S}$ ce qui leur confère un potentiel de consommation d'oxygène, certes peu important mais non-négligeable. En aval du barrage, la concentration en sulfures totaux passe de $43 \mu \mathrm{g} / \mathrm{l}$ au "dégrad" aval, à $0 \mu \mathrm{g} / \mathrm{l}$ à partir de Kérenroch. L'oxydation des sulfures est donc très rapide après le barrage et ne peut expliquer la consommation d'oxygène survenant plus loin.

\subsubsection{Relations possibles entre les deux processus d'oxydation}

Il est bien connu que $\mathrm{H}_{2} \mathrm{~S}$ est un gaz toxique pour les animaux et les végétaux mais aussi pour de nombreux microorganismes. La coïncidence entre la diminution de la concentration des sulfures au niveau 


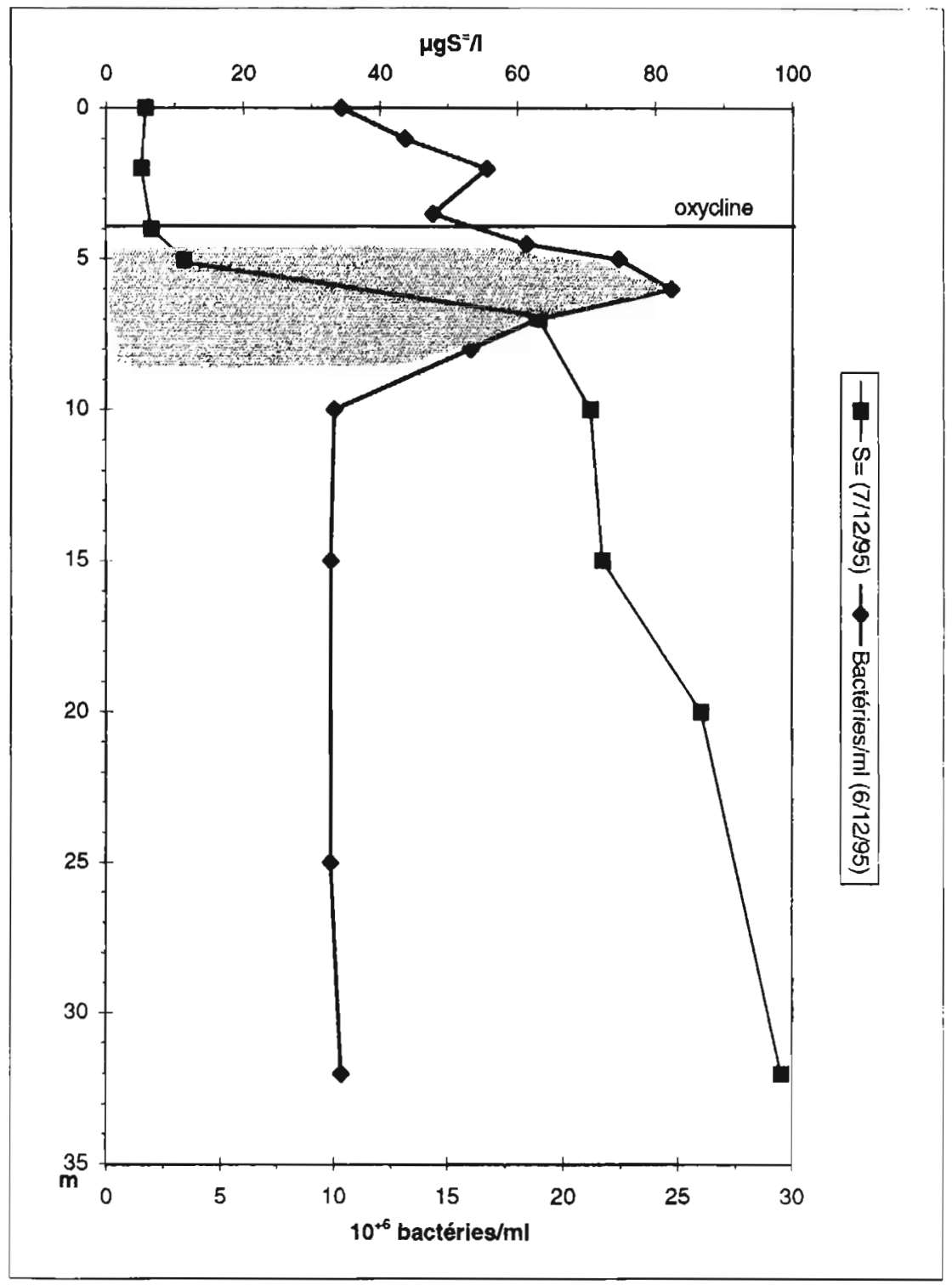

Fig. 11. - Profil d'abondance bactérienne comparé au profil de sulfures totaux a la station BPS en décembre 1995. La zone en grisé représente les pigments bactériens mis en évidence à PetitSaul (cl. Vaquer, ce volume)

Fig. 11. - A comparison between bacterial abundance profile and total sulphide concentrations profile, at the BPS station, during December 1995. The grey area represent bacterial pigments discovered in the water column (see Vaquer in this volume). 
de l'oxycline et le développement de l'activité des méthanotrophes est le point de départ d'une hypothèse de travail afin d'expliquer ce phénomène. Cette observation dans le temps se double d'une observation dans l'espace puisque l'activité méthanotrophique dans le Sinnamary augmente brutalement après Kerenroch, lorsque les sulfures ont disparu (fig. 12).

\section{CONCLUSIONS ET PERSPECTIVES}

Au cours de la période d'étude (février-décembre 1995), nous avons observé dans la retenue une augmentation constante des biomasses bactériennes aérobies ou anaérobies. Cependant, les populations aérobies semblent se stabiliser à la fin 1995.

Le fait marquant est le développement d'un pic de biomasse sous l'oxycline, donc de bactéries anaérobies. La présence de bactério-chlorophylle et l'oxydation rapide des sulfures à ce niveau suggèrent qu'il s'agit de bactéries sulfo-oxydantes chlorophylliennes, mais qui n'ont pu être encore ni cultivées ni déterminées.

Au niveau du fleuve Sinnamary, le développement de la biomasse bac-

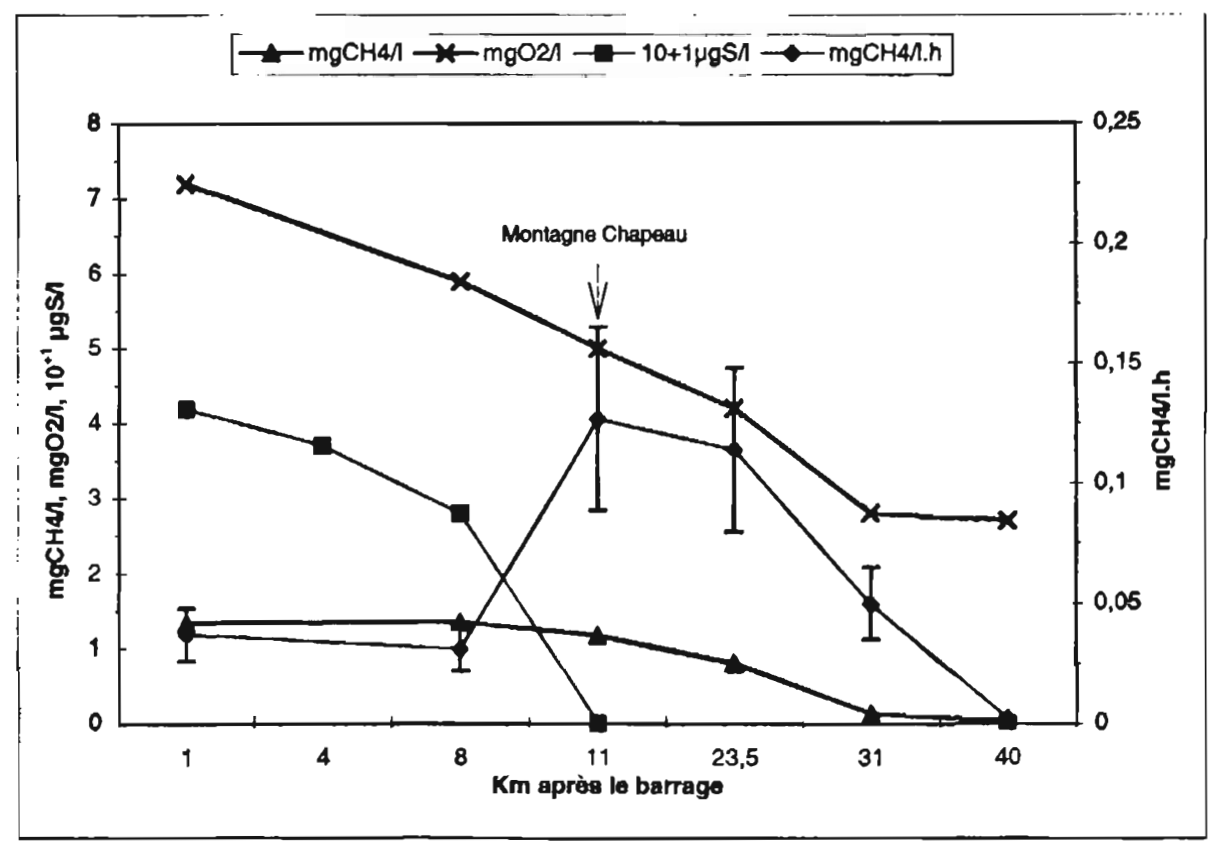

Fig. 12. - Consommation réelle de méthane et concentrations en oxygène, méthane et sulfures le long du fleuve aval en décembre 1995.

Fig. 12. - Real methane consumption with regards to sulphide concentrations, and dissolved oxygen and methane levels downstream, during December 1995. 
térienne tout au long du cours résulte du mélange des substrats réduits contenus dans l'hypolimnion avec les bactéries aérobies et l'oxygène. L'importance de cette croissance dépend du temps de séjour, donc du débit turbiné.

Les taux de croissance spécifiques en zone aérobie sont du même ordre de grandeur que ceux observés dans les lacs eutrophes des zones tempérées. Ils sont 2 à 10 fois plus élevés que ceux de la zone anaérobie ce qui reflète la différence de rendement énergétique. Les taux mesurés par numération microscopique sont bien supérieurs à ceux obtenus par calcul théorique à partir des incorporations de leucine marquée. Les raisons de cette différence, qui n'est pas spécifique de Petit-Saut, restent à déterminer.

En ce qui concerne la consommation de méthane et, corrélativement, d'oxygène, il semble que les bactéries méthanotrophes soient présentes partout en zone aérobie mais que leur activité ne puisse se manifester qu'au niveau de l'oxycline, c'est-à-dire grâce à la présence simultanée de méthane et d'oxygène. Si leur biomasse paraît faible (études biochimiques en cours), leur activité est telle qu'elle supprime l'essentiel de l'émission à la surface du lac. Au niveau du fleuve, c'est le facteur principal de consommation d'oxygène.

On peut s'interroger sur les causes de la longueur de la phase de latence de cette activité. Nous avons avancé l'hypothèse d'une inhibition par la présence de concentrations élevées de sulfures au niveau de l'oxycline, hypo- thèse qui sera vérifiée ou non par une étude en fermenteur au laboratoire. En effet, il existe une coïncidence frappante entre l'activation des méthanotrophes et la diminution des teneurs en sulfures soit par oxydation phototrophique dans le lac, soit par oxydation chimique dans le fleuve Sinnamary.

Finalement, il apparaît que la résolution des problèmes techniques posés par l'exploitation du barrage débouche sur un grand nombre d'interrogations scientifiques qui ne manquent pas d'intérêt. Espérons que la conjonction de compétences diverses permettra d'apporter quelques réponses.

\section{REMERCIEMENTS}

Nous tenons à remercier toute l'équipe du Laboratoire Environnement de PetitSaut, pour le soutien technique apporté tout au long de cette étude.

Nous remercions également Muriel Petit et Pierre Lavandier, pour leur aide cruciale lors de la mise au point des protocoles de mesures de l'incorporation de leucine tritiée.

\section{RÉFÉRENCES BIBLIOGRAPHIQUES}

Bratbak G. 1985. Bacterial biovolume and biomass estimations. Applied and Environmental Microbiology 49: 14881493.

Cline J.D. 1969. Spectrophotometric determination of hydrogen sulfide in natural waters. Limnology and Oceanography 14 (3) : 454-458.

Couturier A. 1995. Methodes appliquées à l'écologie microbienne dans deux mi- 
lieux lacustres: Pareloup (Aveyron) et Layrac (Tarn) DEA Laboratoire d'Hydrobiologie, UPS Toulouse.

Edeline F. 1993. L'Epuration biologique des Eaux. Liège. CEBEDOC.

Furhman J.A. and Azam F. 1982. Thimidine incorporation as a measure of heterotrophic bacterioplankton production in marine surface waters: evaluation and field results. Marine biology 66 : 109-120.

Garcia-Cantizano J., Calderon-Paz J. and Pedros-Alio C. 1994. Thymidine incorporation in Lake Ciso: problems in estimating bacterial secondary production across oxic-anoxic interfaces. FEMS Microbiology Ecology 14 : 5364.

Jannasch H.W. 1975. Methane oxidation in Lake Kivu (Central Africa). Limnology and oceanography 80 : 860-864.

Joergensen L., Degn H. 1987. Growth rate and methane affinity of a turbidostatic and oxystatic continuous culture of Methylococcus capsulatus (bath). Biotechnol. lett. $9: 71-76$.

Jones J.G. 1970. Studies on Freshwater Bacteria : Effect of Medium Composition and Method on Estimates of Bacterial population. J. Appl. Bact. 33: 679-686.

King G.M. and Blackburn T.H. 1996. Controls of methane oxidation in sediments. Mitt. Internat. Verein. Limnol. 25 : 25-38.

Kirchman D., K'Nees E., Hodson R. 1985. Leucine incorporation and its potential as a mesure of protein synthesis by bacteria in natural aquatic systems. Appl. Environ. Microbiol. 49 : 599-607.

Mackay D., Shiu W.Y. 1981. Rewiew of Henry's Law constants for chemicals of environmental interest. J. Phys. Chem. Ref. Data 26 (2) : 259-265.

Petit M. 1993. Etude des microorganismes planctoniques en milieu lacustre (lac de Pareloup) et fluvial (Garonne) DEA Laboratoire d'Hydrobiologie, UPS Toulouse.
Pochon J. and Tardieux P. 1962. Techniques d'analyse en microbiologie du sol. Edit. de la Tourelle, Saint-Mandé/Seine. $112 \mathrm{p}$.

Porter K.G. and Feig Y.S. 1980. The use of DAPI for identifying and counting aquatic microflora. Limnol. Oceanogr. 25 : 943-948.

Riemann B. 1984. Determining growth rates of natural assemblages of freswater bacteria by means of $3 \mathrm{H}$-thymidine incorporation into DNA: comments on methodology. Archiv für Hydrobiol. Beih. Ergebn. Limnol. 19 : 67-80.

Rudd J.W., Hamilton R.D., Campbell N.E.R. 1974. Measurement of microbial oxidation of methane in lake water. Limnology and Oceanography 19 (3): 519-524.

Rudd J.W.M., Hamilton R.D. 1975. Methane oxidation in a eutrophic Canadian Shield lake. Verh. Internat. Verein. Limnol. 19 : 2669-2673.

Rudd J.W., Furutani A., Flett R.J., Hamilton R.D. 1976. Factors controlling methane oxidation in shield lakes: the role of nitrogen fixation and oxygen concentration. Limnology and Oceanography 21 (3) : 357-364.

Senvais P. 1990. estimation de la production bactérienne en milieu marin par mesure du taux de synthèse protéique. Oceanolgica Acta 13 (2) : 229235.

Servais P. and Lavandier P. 1993. Estimation de la production des bactéries hétérotrophes dans les eaux douces naturelles: comparaison de l'incorporation de $3 \mathrm{H}$-thymidine et de ${ }^{3} \mathrm{H}$-leucine. C.R. Acad. Sci. Paris, Sciences de la Vie 316: 642-646.

Simon M. and Azam F. 1989. Protein content and protein synthesis rates of planktonic marine bacteria. Mar. Ecol. Prog. Ser. 51 : 201-213.

Sweerts J.PRA, Dekkers T.M.J. and Cappenberg T.E. 1996. Methane oxidation 
at the sediment-water interface of shallow eutrophic Lake Loosdrech and deep meso-eutrophic Lake Vechten in cycling of reduced gases in the hydrosphere. Mitt. Internat. Verein. Limnol. 25 : 197-203.

Torreton J.P., Bouvy M. 1991. Estimating bacterial DNA synthesis from ${ }^{3} \mathrm{H}$-thymidine incorporation: discrepencies among macromolecular extraction procedures. Limnology and Oceanography 36 : 299-306.

Trousselier M., Albat M., Andre P. et Baleux 1985. Dénombrements directs des bactéries dans les milieux aquatiques par microscopie en épifluorescence: distribution et précision des mesures. Revue française des Sciences de l'eau 4 : 35-49.

Whittenbury R., Phillips K.C. and Wilkinson J.F. 1970. Enrichment, isolation and some properties of methane-utilising bacteria. J. of Gen. Micro. 61 : 205-218.

Wicks R.J., Robarts R.D. 1987. The extraction and purification of DNA labelled with [methyl- ${ }^{3} \mathrm{H}$ ]-thymidine in aquatic bacterial production studies. Journal of Plankton Research 9: 1159-1166.

Winding A.1992. ${ }^{3} \mathrm{H}$-thymidine incorporation to estimate growth rates of anaerobic bacterial strains. Appl. Environ. Microbiol. 58 (8) : 2660-2662. 